\title{
FLOOD MONITORING USING NDWI AND MNDWI SPECTRAL INDICES: A CASE STUDY OF AGHQALA FLOOD-2019, GOLESTAN PROVINCE, IRAN
}

\author{
F. Khalifeh Soltanian ${ }^{1}$, M. Abbasi ${ }^{2, *}$, H. R. Riyahi Bakhtyari ${ }^{3}$ \\ ${ }^{1}$ Dept. of Forest Science, Faculty of Natural resource and Earth Science, Shahrekord University, Shahrekord, Iran - \\ faezeh.kh.soltanian@gmail.com \\ ${ }^{2}$ Dept. of Forest Science, Faculty of Natural resource and Earth Science, Shahrekord University, Shahrekord, Iran. \\ mozhgan.abasi@gmail.com \\ ${ }^{3}$ Dept. of Forest Science, Faculty of Natural resource and Earth Science, Shahrekord University, Shahrekord, Iran. \\ reza_reyahi@yahoo.com
}

Commission VI, WG VI/4

KEY WORDS: Flood area, NDWI, MNDWI, Landsat-8, Aghqala city

\begin{abstract}
:
Assessment of changes of water bodies and vegetation by traditional methods is very difficult and costly. The use of satellite data makes it possible to study water bodies and vegetation more accurately and cost effectively. Accordingly, various digital methods have been developed to discover and detect changes of earth's surface features. Flood is one of the important factors contributing to the destruction of natural resources. The purpose of this research is to evaluate the flood areas in the Aghqala area in Golestan province of Iran. The level of water bodies in the spring of 2018 and 2019 was compared and evaluated based on the NDWI and MNDWI indices using Landsat images. The results showed that water bodies' area in the spring of 2018 was $24.13 \mathrm{~km}^{2}$ which increased to $185.34 \mathrm{~km}^{2}$ at 2019 using NDWI; while the MNDWI due to the excessive sensitivity to the water considered agriculture wetlands as an area of water bodies. Therefore, the NDWI yielded more logical results. Also, change detection methods based on spectral and radiometric information using indices are more accurate than the classification maps and more changes can be shown. Using satellite imagery to monitor changes is essential to facilitate the planning of natural hazards management.
\end{abstract}

\section{INTRODUCTION}

Flooding is one of the most common and destructive natural hazards affecting human life and creating many economic problems around the world. Therefore, accurate monitoring of flood events is increasingly necessary to gain insight about both causes and remedies (Refice et al., 2017; Ghofrani et al., 2019). The first concern in flood management plans is mapping flood area. The traditional methods using hydraulic and topographic modelling to simulate and visualize flood area are sometimes not very accurate, high costs and time consuming. Remote sensing is a strong tool which offers some long recognized advantages, such as the capability of providing synoptic information over wide areas at low costs, the reliability of data acquisition schedule, the immunity to local hindrances such as site accessibility or dangerous environmental conditions, etc. (Refice et al., 2017). Change detection is a process that allows observing and recognizing the time series differences of features, complications, and patterns of the earth's surface.

Since various phenomena such as water and plant objects have different pigment levels and so different reflectance, using indices to distinguish different bodies is necessary. The results of many researches indicate the efficiency of using indices to estimate the quantitative parameters of the surface of plants and water. Water Index (NDWI) using Near Infrared (NIR) and green wavelengths can highlight open water features, which modified by $\mathrm{Xu}$ (2006) by substituting the middle infrared band for NIR band and called it MNDWI. The NDWI index is designed to maximize the reflection of water by using green wavelengths, minimizing the low reflectance of NIRs by water features, and the high reflectance of NIRs by vegetation and soil features (Xu, 2006). Kish (2002) used remote sensing technique to evaluate the surface area of Lake Jackson and Florida based on climatic elements. The results of these time series studies showed that flood-water fluctuations can be monitored and evaluated accurately by remote sensing technology.

Golestan province in the north of Iran has been exposed to short and long rains every year, which has resulted in severe and destructive floods. The heavy rainfall in this province in the year 2001 led to a flood, which according to international census had the first rank of human casualties in the world (Sharifi et al., 2012). This event was repeated again in May 2019. Therefore, the purpose of this study was to monitor the water level changes before and after the flood in the city of Aghqala in Golestan province based on NDWI and MNDWI indices obtained from Landsat-8 OLI imagery in 2018 and 2019. As well as the change detection methods including image change workflow and classification methods were compared.

\section{MATRIAL AND METHODS}

\subsection{Study area}

The city of Aghqala with an area of $1763 \mathrm{~km}^{2}$ is located in the geographical range of $54^{\circ} 14^{\prime}$ to $54^{\circ} 51^{\prime}$ in latitude and $30^{\circ}$ $37^{\prime}$ to $36^{\circ} 55^{\prime}$ in longitude in northern Golestan province. This city is located on the sides of the Gorganroud River and 18

\footnotetext{
* Corresponding author
} 
kilometers north of Gorgan. In general, the climate of the region is warm and semi-arid. The average rainfall in this area is about $360 \mathrm{~mm}$ annually, the average annual temperature is $18.3^{\circ} \mathrm{C}$ and the dry period lasts from 6 to 7 months a year (fig 1).

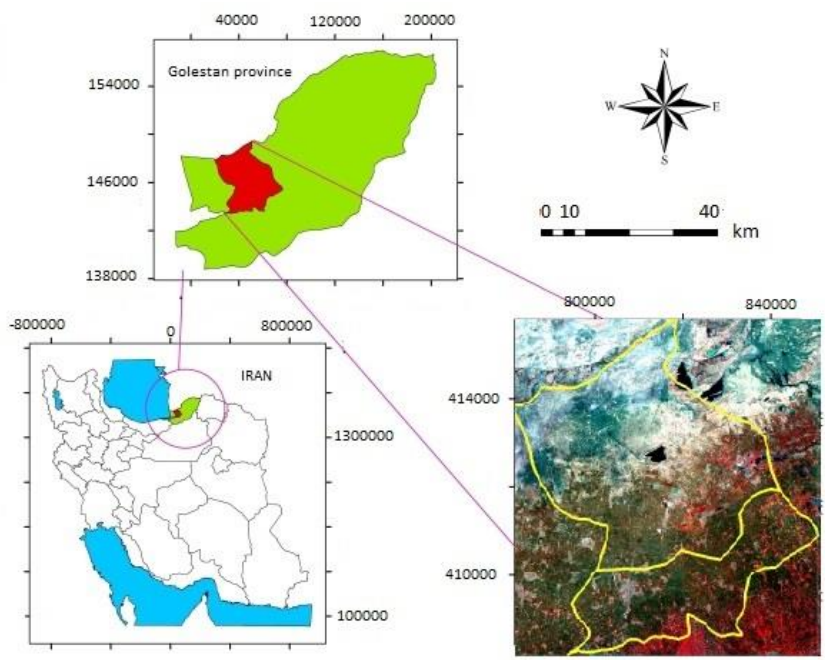

Figure 1. Location of study area

\subsection{Satellite image processing}

Radiometric and atmospheric corrections on Landsat-8 OLI images from 2018 and 2019 was performed (fig. 2). Then, NDWI (equation 1) and MNDWI (equation 2) indices have been calculated.

NDWI $=\frac{\text { Green }- \text { NIR }}{\text { Green + NIR }}$

MNDWI $=\frac{\text { Green }- \text { MIR }}{\text { Green }+ \text { MIR }}$

where $\quad$ Green $=$ Green band

NIR $=$ Near infrared band

$\mathrm{MIR}=$ Middle infrared band

The level of water bodies before and after the flood has been obtained using the band threshold to region of interest (ROI) and the range of min and max of pixels has been determined. The surface of the watersheds is compared before and after the flood. In the first method the changes were detected with the "image change workflow" method. In another method, the training area for each class were selected on the image (ROI), and then different supervised classification methods were performed for mapping water land bodies for two-time series. We compared the results of the classification mapping-based changes with the results of spectral and radiometric information-based detection of changes.

\section{RESULT}

The results showed that water bodies' area in the spring of 2018 was $24.13 \mathrm{~km}^{2}$ which increased to $185.34 \mathrm{~km}^{2}$ at 2019 using NDWI (fig. 3). The Most of the study area is paddy fields, since vegetation has relatively high reflectance in NIR region, so the NDWI could not take water under vegetation into account and ultimately underestimate the inundated area (Memon et al, 2015). While the MNDWI (fig 4) due to the excessive sensitivity to the water considered paddy fields as an area of water bodies (Blackmore et al, 2016); that is why MNDWI has significantly overestimated the inundated area. Therefore, the NDWI yielded more logical results. Blackmore et al, (2016) compare these two indices on Landsat- 8 images at dry and wet lands with vegetation cover, they found NDWI appeared to be more able to predict variations in dry conditions when recent rainfall was significant because of responding to vegetation moisture rather than surface moisture. However, due to the presence of wet-to-inundate paddy fields in this study, the prediction of MNDWI index from these areas are as flood class which is not true. The blue areas are the water zone which were not in 2018 and will be created in 2019 and include flood areas (fig. 5). The MNDWI index shows the area of the water bodies before the flood of $61.06 \mathrm{~km}^{2}$ and after the flood of $405.50 \mathrm{~km}^{2}$. Most of the changes in the northwest areas of Aghqala city have occurred (fig. 4). The MIR band used in the MNDWI index has an excessive sensitivity to water area, hence, some agricultural area like paddy field are considered as water areas. While the NDWI index yielded better results, it distinct the areas that were really water. Khosravani et al. (2017) have shown that the NDWI index is more accurate than the other indices for change detection of lake Parishan. Ghofrani et al., 2019 found that NDWI and MNDWI indices performed well, but water features were enhanced better in the NDWI-derived image. The change detection methods derived from spectral and radiometric information based on the indices (fig 4 left) are more accurate than the change detection methods based on classification maps, and can show more changes (fig. 5 right).
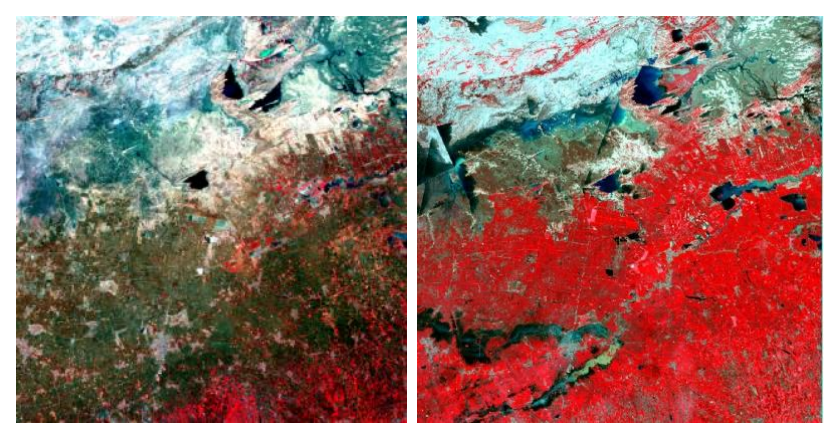

Figure 2: The results of radiometric and atmospheric corrections on Landsat-8 OLI images from 2018 (before flooding, left image) and 2019 (after flooding, right image).

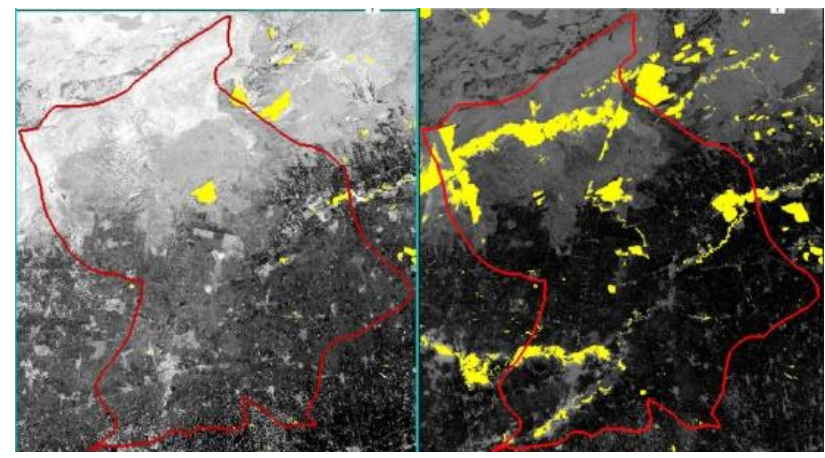

Figure 3. Extracted water bodies from NDWI image before (left) and after (right) flood, water bodies area appears as yellow pixels. 


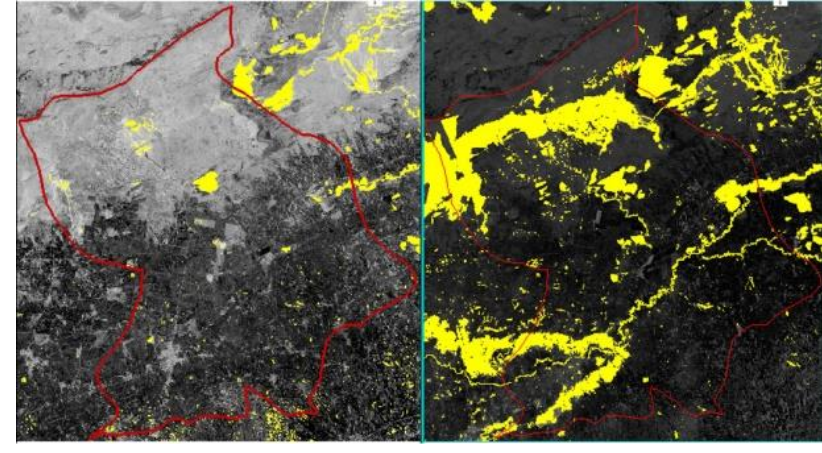

Figure 4. Extracted water bodies from MNDWI image before (left) and after (right) flood, water bodies area appears as yellow pixels.

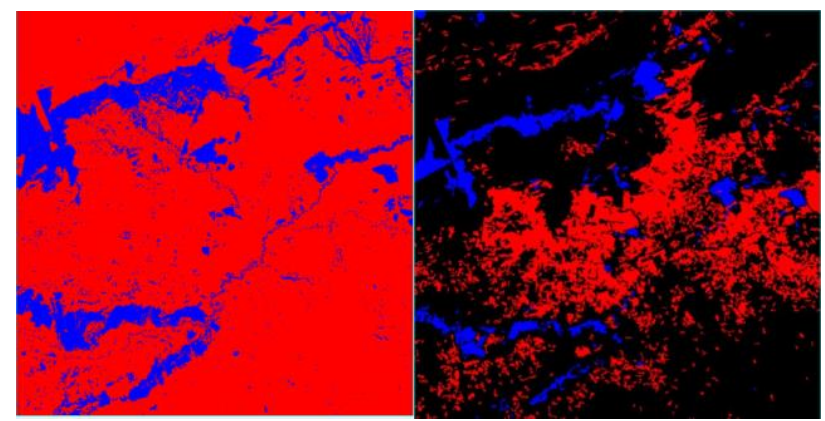

Figure 5. Changes detection map obtained from workflow method, blue area shows increased water bodies from NDWI image (left) and classified images in 2018 and 2019 (right).

\section{CONCLUTION}

The results of this researches show that the NDWI index is more accurate than the MNDWI index for extraction of surface water with vegetative area from Landsat data. Blackmore (2016) confirmed that NDWI seem more sensitive to sites with vegetation.

The change detection methods derived from spectral and radiometric information (workflow method) based on the indices are more accurate than the change detection methods based on classification maps. Accurate flood monitoring system to gain insight about both causes and remedies and make early warnings by the specialist is increasingly necessary. Use of this low-cost method to map flooded area for crisis condition could directly improve the ability to manage and monitor near realtime flood disaster.

\section{REFERENCES}

Blackmore, D. S. 2016. Use of Water Indices Derived from Landsat OLI Imagery and GIS to Estimate the Hydrologic Connectivity of Wetlands in the Tualatin River National Wildlife Refuge.

Ghofrani, Z., Sposito, V., \& Faggian, R. 2019. Improving flood monitoring in rural areas using remote sensing. Water Pract Tech, 14(1), 160-171.

Kish, S. A., Balsillie, J. H., \& Milla, K. 2001. A remote sensing and GIS Study of Long-Term water mass balance of Lake Jackson. In Twelfth Annual Conference of Florida Lake Management, Tallahassee, Florida, USA.
Khosravian, M., Entezari, A.R., Rahmani, A., Baagh M., 2018. Monitoring the Disturbance of Lake District Water Level Changes Using Remote Sensing Indices, Hydrogeomorghplogy, 4(13), 99-120.

Memon, A. A., Muhammad, S., Rahman, S., \& Haq, M. 2015. Flood monitoring and damage assessment using water indices: A case study of Pakistan flood-2012. The Egyptian Journal of Remote Sensing and Space Science, 18(1), 99-106.

Refice, A., D'Addabbo, A., \& Capolongo, D. (Eds.). (2017). Flood Monitoring through Remote Sensing. Springer.

Sharifi, F., Samadi, S. Z., \& Wilson, C. A. 2012. Causes and consequences of recent floods in the Golestan catchments and Caspian Sea regions of Iran. Nat Hazards, 61(2), 533-550.

Xu, H. 2006. Modification of normalised difference water index (NDWI) to enhance open water features in remotely sensed imagery. Int. J. Remote Sens., 27(14), 3025-3033. 